DOI: $10.22559 /$ folklor.1039

folklor/edebiyat, cilt: 25 , sayı: 100, 2019/4

\title{
Eğitim Sosyolojisi Açısından İlhan Başgöz'ün Kuramsal Yaklaşımı
}

\section{The Theoretic Approach of Illhan Başgöz in Terms of Sociology of Education}

\section{Mehmet Devrim Topses*}

$\ddot{O} \mathbf{z}$

Eğitim kurumu toplumsal yapının bir parçasıdır. Bu nedenle onun ekonomi ve siyaset kurumlarıyla birlikte incelenmesi gerekir. İlhan Başgöz'ün Türkiye'de Cumhuriyet dönemi eğitim uygulamalarına yönelik incelemeleri, eğitim sosyolojisi açısından özellikle iki noktadan önem taşımaktadır. Birinci olarak Başgöz, Cumhuriyet dönemi eğitim sistemini ekonomik ve siyasal temelleriyle etkileşim içinde ele almıştır. Üstelik çok derin olmasa bile, Köy Enstitülerine karşı çıkan toplumsal kesimlerin sınıfsal tabanına yönelik bazı değerlendirmelerde bulunduğu bile görülebilir. İkinci olarak ise Başgöz, tek parti dönemi eğitim uygulamalarına yakından tanıklık etmiş, bu dönemi yaşamış bir bilim insanıdır. Çocukluğu ve ilk gençliği bu dönemlere denk gelmektedir. Günümüzde eğitim kurumunun tarihsel geçmişine yönelik araştırmalarda en büyük sorun veri toplamak, sıklıkla başvurulan yöntem ise literatür ve arşivlere başvurmaktır. Bu yöntem geçerli ve kabul edilebilir olsa da veriye ulaşma yolunda bazı sınırlılıklar barındırmaktadır. İlgili tarihsel sürecin, bu dönemin içinden gelen bir bilim insanınca ele alınmış olması ise eğitim sosyolojisi için eşsiz bir veri kaynağı olarak kabul edilmelidir.

Doç. Dr., Çanakkale Onsekiz Mart Üniversitesi Fen-Edebiyat Fakültesi Sosyoloji Bölümü. devrimtopses@comu. edu.tr. ORCID ID/0000-0003-2753-6369. 
$\mathrm{Bu}$ makalede Başgöz'ün Cumhuriyet dönemi eğitim uygulamalarına dönük gözlemlerinden yola çıkarak ulaştığı iki temel kuramsal yaklaşıma yer verilecektir. $\mathrm{Bu}$ kuramsal yaklaşımlar Başgöz tarafından oluşturulup tasniflenmiş değildir. Araştırmacı tarafından makalenin konusu olarak seçilip, kuramsal dayanaklarıyla birlikte ortaya konulmuştur. Söz konusu başlıklar şöyle belirtilebilir: Birinci olarak Başgöz, toplumsal sorunların çözümünde eğitimin tek başına belirleyici bir gücü olabileceği yaklaşımını kabul etmemiştir. Eğitimin siyaset ve ekonomik koşulların etkisi altında biçimlenip yeni işlevler kazanacağı yaklaşımının altını çizmiştir. Örneğin egemen toplumsal sınıfların çıkarlarına ters düşen ya da onların desteklemediği bir eğitim uygulaması, toplumsal yapıyı ilerici yönde değiştiremeyecektir. İkinci olarak ise Başgöz, eğitim kurumunun toplumsal gerçeklere uygun ve toplumsal ihtiyaçları karşılayacak biçimde örgütlenmiş olmasının önemini belirtmiştir. Örneğin köyün ve alt toplumsal sınıfların benimseyebileceği tek eğitim uygulaması, onların ihtiyaçlarıyla bütünleşmiş bir eğitim düzenidir. Bu görüşleriyle 1930'lu yıllarda Amerika'da ortaya çıkan eğitimde yeniden yapılandırmacı görüşlerden ayrılarak Marksist kuramcılara yaklaşır. Makalede söz konusu kuramsal yaklaşımların daha ayrıntılı bir tasnifine ve açıklamasına yer verilmiştir. Tümüyle literatür taramasına dayalı betimsel bir yöntem kullanılmıştır.

Anahtar sözcükler: ĕgitim sosyolojisi, köy enstitüleri, Türk modernleşmesi, toplumsal değişme, toplumsal sınıflar

\begin{abstract}
The education is a part of the social structure. Therefore, it should be examined together with the economy and politics. İlhan Başgöz's studies on the education practices in the Republican period in Turkey are especially important in two points in terms of sociology of education. First, Başgöz examined the education system of the Republican period in interaction with its economic and political foundations. Moreover, it can be seen that, even if it is not very deep, he makes some interpretations on the class foundation of the social segments opposing the Village Institutes. Second, Başgöz is a scientist who witnessed and experienced the educational practices of the single-party period. His childhood and early youth coincided with this period. Today, the biggest problem in the studies on the historical background of the education is to collect data and the most commonly used method is to resort to the literature and archives. Although this method is valid and acceptable, it has some limitations in accessing the data. The fact that the relevant historical process was examined by a scientist coming from this period should be regarded as a unique data source for the sociology of education.

In this study, the two fundamental theoretic approaches which Başgöz reached through his observations on the educational practices in the Republican period will be included. These theoretic approaches have not been created and classified by Başgöz. This was chosen by the researcher as the subject of the study and put
\end{abstract}


forward with its theoretical basis. The topics in question are as follows: First, Başgöz did not accept the approach that the education alone could have a decisive power in solving the social problems. He underlined the approach that the education would take shape and gain new functions under the influence of the politics and economic conditions. For example, an educational practice that contradicts or does not support the interests of the dominant social classes will not progressively change the social structure. Second, Başgöz underlined the importance of that the educational should be organized in a way that is in accordance with the social realities and meets the social needs. The only educational practice the village and the lower social classes can adopt is an educational system integrated with their needs. With these views, he diverges from the reconstructive approaches in education that emerged in America in the 1930s and comes close to the Marxist theorists. A more detailed classification and explanation of these theoretic approaches were included in the study. A descriptive method based on a literature review was used.

Keywords: sociology of education, village institutes, Turkish modernization, social change, social classes

\section{Giriş}

Gerçekte Başgöz’ün edebiyat ve halk kültürünün yazılı kaynakları üzerine yapmış olduğu incelemeler, onun öncelikli olarak bir folklor araştırmacısı olduğunu göstermektedir. Bununla birlikte Türkiye'de Cumhuriyet dönemi eğitim sisteminin tarihsel ve kuramsal temellerine yönelik incelemeleri, İlhan Başgöz'ün eğitim sosyolojisi açısından incelenmesini de önemli bir gereklilik duruma getirmektedir. Bu gereklilik İlhan Başgöz'ün yalnızca eğitim ve toplum arasındaki ilişkinin çeşitli boyutlarını saptamış olmasından kaynaklanmaz. 20. yüzyılın başlarında gerçekleşen Türk devriminin eğitim felsefesine ve uygulamalarına yakından tanıklık etmiş olması, literatür ve arşiv incelemelerini bu tanıklığıyla birleştirmiş olmasından ileri gelir. Eğitim sosyolojisinin beslendiği asıl kaynak, teoriler ve çeşitli anlatılar değil, teoriyi sınayan ve gerektiğinde onu değiştiren uygulama alanlarıdır. Uygulama ya da yaşamın kendisi, herhangi bir bilim dalının bütün kuramlarını destekleyebileceği gibi, onları değiştirebilmeli ya da onlara yeni yollar açabilmelidir. Başgöz'ün Cumhuriyet dönemi eğitim sistemine ilişkin uygulamaya dayalı gözlemleri iki temel başlık altında toplanabilir. Bu başlıkların ikisi de, birbirine bağlı olduğu gibi birbirini belirler. Makalenin konusu, aşağıdaki başlıkların oluşturulması ve tartışılmasıdır.

\section{Eğitim ve toplumsal değişme ilişkisi}

20. yüzyılın başında Amerika Birleşik Devletleri'nde ortaya çıkan yeniden yapılandırmacı teoriler, toplumsal değişme sürecinde eğitim kurumuna öncelikli bir işlev tanımışlardır. Örneğin George Counts ve Bremeld gibi kuramcılar mevcut toplumsal sorunların çözümünde eğitim kurumunun belirleyici bir araç olduğunu ileri sürmekteydiler (Eskicumalı, 2003). Başgöz ise eğitimde yeniden yapılandırmacı teorilere karşı çıkarak, toplumsal koşullar uygun olmadığında eğitimin tek başına köklü bir değişim yaratamayacağını vurgulamıştır. Başgöz 
(2005: 9)'e göre söz konusu toplumsal koşullar siyasetin, hukukun ve ekonominin de devrimci bir değişim sürecinin içinde bulunmasıdır. Bu koşullar gerçekleşmediğinde eğitimden büyük toplumsal sorunların ilerici yönde çözümünü bekleyemeyiz. Başgöz'ün bu saptamaları, Marksist gelenekten gelen Althusser, Bowles ve Gintis gibi bazı yapısal fonksiyonalistlerin kuramsal yaklaşımlarıyla büyük ölçüde benzeşmektedir. Onlar da halkçı bir eğitimin yalnızca halkçı bir hükümet ve ekonomi politikasıyla birlikte yürüyebileceğinin altını çizen değerlendirmeler yapmışlardır (Althusser, 2014). Aslında bakıldığında Türkiye, eğitim alanında "köy eğitmenleri” ve "köy enstitüleri” gibi devrimci hamlelere giriştiğinde Başgöz'ün savunduğu derin toplumsal değişimleri içeren kuramsal değerlendirmelere yaklaşmış, 20. yüzyılın ikinci yarısından sonra tümüyle Amerikan eğitim sisteminin etkisine girdiğinde ise yeniden yapılandırmacı teorilere uymaya başlamıştır (Başaran, 1974: 65-80). Türkiye eğitim tarihinin özellikle 20. yüzyıldan sonraki gelişim süreci bunu göstermektedir.

Başgöz'ün eğitim sosyolojisi açısından taşıdığı önem, söz konusu saptamasını Türkiye eğitim tarihinden verdiği örnekler yoluyla kanıtlamış olmasıdır. Siyaset ve ekonomi, eğitim felsefesi ve uygulamaları üzerinde her tarihsel dönemde etkili olmuştur. Çeşitli örnekler verecek olursak Türkiye'de harp okulları, yeniçeri ocağının kaldırılmasından sonra kurulmaya başlamıştır. Asker okullarında yeni silah tekniğini ve onun dayandığı bilgileri öğrenmek zorunluluğu, Osmanlı eğitim sistemindeki ezber geleneğini bozmuştur. Tanzimat dönemi ve 1858 Arazi Kanunnamesi, Türk eğitim felsefesinde 19. yüzyıldan sonra memur yetiştirme amacının toplumsal zeminini oluşturmuştur. Osmanlı eğitim, düşünce ve yazın hayatının ilk büyük canlanması, 1908 devrimiyle birlikte eski saltanat elitinin siyasal iktidardan uzaklaşmasına denk gelir. Cumhuriyet'in ilk yıllarında eşraf ve toprak ağalarının devrimci sayılabilecek eğitim uygulamalarını engellemelerinin nedeni, toplumsal çıkarlarının tehlike altına girmiş olmasıdır. Karma eğitime geçilmesinin önemli belirleyicilerinden birisi, Türkiye'nin karşılaştığı ekonomik güçlükler olmuştur. Son bir örnek ise Türkiye'de okul kitapları üzerindeki devlet tekelinin kaldırılması ve serbest kitap rejimine dönülmesi, çok partili yaşama geçildiği dönemlerden hemen sonra gerçekleşmiştir (Başgöz, 2005:1-129). Söz konusu tarihsel örneklerin tümü, eğitim kurumunun ekonomik ve siyasal koşulların etkisi altında değişim gösteren bir ilişki sistemi olduğunu göstermektedir.

Eğitim, siyaset ve ekonomi arasında varlığı saptanmış olan bu ilişkiler, Başgöz'ün önce Meşrutiyet ve sonra Cumhuriyet dönemine ilişkin daha somut incelemeleriyle genişletilmiştir. Örneğin Türkiye'de devrim dönemlerinde eğitimden beklentiler yükselmesine karşın, Jön Türkler iktidara geldiklerinde temel ekonomik sorunlar üzerinde hiçbir düzeltme hareketine girişmemişlerdir. Cumhuriyet döneminde yeni devreye giren idareciler ise toplumun sınıfsal dengesinde ve toprak mülkiyetinde köklü değişmelere gitmek istememişlerdir. Köylerde sosyal ve ekonomik değişimi modernleştirecek ekonomik önlemler alınmadığı için de eğitmenin tek başına bu işin altından kalması olanak dışı kalmıştır. Ya da devletin köyde ekonomik ve toplumsal bir reform planı bulunmadığı ve öğretmenler çok yönlü bir kalkınma çabasının birer parçası olarak gönderilmedikleri için toplumsal değişme sürecindeki eğitim denemeleri başarıya ulaşamamıştır (Başgöz, 2005: 50, 195-196). Böylece Başgöz, Türk modernleşmesinde eğitim kurumunun başarısızlığının maddi toplumsal çelişkilerini göstermiş olmaktadır. 
Görüldüğü gibi bu toplumsal temeller manevi içerikli değil, madde kaynaklıdır. Türkiye’de 19. yüzyıl sonrasındaki modernleşme sürecini çözümlemeye girişen sosyologların önemli bir çoğunluğu, bu tarihsel süreci idealist bakış açılarıyla açıklama eğiliminde olmuşlardır. Örneğin Şerif Mardin, Türk modernleşmesinin en büyük çelişkisi olarak "geleneğe ters düşülmesi” ya da “gelenekten uzaklaşılması”nı göstermiştir. Çünkü Mardin’e göre gelenekten kopuş, aynı zamanda halktan kopuştur (Mardin, 2017: 35-77). Oysa toplumsal yapı ekonomik bir temel üzerine yükselir. Mardin, toplumsal yapıya maddi ve sınıfsal bir açıdan bakmadığı için geleneğin aslında hangi toplumsal sınıfların çıkarlarını temsil ettiğini gerçeğe uygun biçimiyle çözümleyememiştir. Diğer yandan yukarıda açıklandığı şekliyle Başgöz'e göre devrim dönemlerinde eğitim amaçlarındaki başarısızlığın öncelikli nedeni "geleneğe ters düşülmesi” değil, alt sınıfların yaşam koşullarını iyileştirecek ekonomik önlemlerin alınmayışıdır. Konuyu bu şekilde ortaya koymak, toplumsal yapının ekonomik-sınıfsal merkezli işleyişine çok daha uygundur.

Başgöz'ün kuramsal yaklaşımında konuya ilişkin bazı sınıfsal çözümlemeler yapılmış olması, başka bir özgünlüktür. Örneğin bu saptamalara göre tarım okullarının çiftlikler halinde kurulması ya da iş temeline göre kurulan ve toplumsal yapıyı değiştirmeye odaklanmış bir eğitim felsefesine en büyük eleştiri ve karşı çıkışlar il idare kurullarından gelmiştir. İl idare kurulları ise eşraf içerikli örgütlenmelerdir. Üyeleri çoğunlukla büyük çiftçi, büyük tüccar, yerli eşraf ve diğer yerel otoritelerden oluşmaktadır (Başgöz, 2005: 101). Başgöz (2019: 44)'e göre bu kurullar Cumhuriyet'in temel ilkelerine olduğu gibi Cumhuriyet'in bütün vatandaşların okutulması yönündeki amaçlarına da karşı çıkmışlardır. Benzer şekilde Cumhuriyet'in eğitim reformlarına paralel olarak yürürlüğe koymayı amaçladığı toprak reformu tasarısına en sert ve köklü karşı çıkışlar toprak ağalarından gelmiştir (Başgöz, 2019: 56). Gerçekten de yerli ve yabancı çoğu toplumbilimci görmekten kaçınsa da, bütün toplumsal olguların maddi ya da sınıfsal bir temeli bulunmaktadır. Sosyal bilimlerde toplumsal olguların böyle sınıfsal bir zeminde ele alınması, geç kabul görmüş ve ender kullanılan bir yöntemdir.

\section{Toplumsal gerçeklere uygun eğitim düzeni}

İkinci nokta, Başgöz'ün yaklaşımında eğitimin toplumsal ihtiyaçların bir ürünü olarak görülmüş olmasıdır. Toplumsal kurumlar, yalnızca toplumsal ihtiyaçların ürünleri olarak ortaya çıkıp geliştiklerinde benimsenebilirler. İhtiyaçların dışında ve onları karşılamayan kurumsal yapıların benimsenip gelişebilmesi olanaksızdır. Başgöz'e göre eğitim toplumsal koşulların bir ürünü olduğu gibi, toplumsal ihtiyaçlara yanıt verebildiği ölçüde olumlu işlevler yüklenebilir. Örneğin kentsoylu (burjuva) eğitim felsefesi açısından bakıldığında okul, bilgi veren, ışık saçan bir ocak olarak görülmüştür (Başaran, 1974: 50). Tarıma dayalı, kulluk-kölelik ilişkileri altında ezilen, yoksul bir toplumsal yapıda ise okulun bu şekilde yalnızca bilgi kaynağı olarak görülmesi ayırt edici kesin bir hatadır. Köye dayalı toplumun gerçeklerinden ve ihtiyaçlarından uzaklaşmaktır. Gerçekten de dönemin toplumsal koşulları içinde okul sadece bilgi kaynağı olarak görüldüğünde eğitim sistemi başarısız olmuş, köyün ekonomisiyle birleştiği dönemlerde ise küçük üretici ve diğer emekçi sınıflarca benimsenmiştir. 
Örneğin Başgöz (2005: 80-83)'ün yaklaşımında Türkiye'de köylülük, küçük üreticilik ve diğer emekçilerden oluşan alt sınıfların devletten kendilerine gelecek bütün uygulamalara kuşkuyla baktıkları belirtilmiştir. Eğitimin ise benzer şekilde, Türkiye'de köylüler tarafından "efendilerin istek ve beklentilerini barındıran" bir kurum olarak görülmesi kaçınılmaz olmuştur. Buna karşın "köy eğitmenleri” ve sonrasındaki "köy enstitüleri" uygulamalarında eğitim, toplumsal yapının maddi ihtiyaçlarıyla birleştiğinde bu kuşkular dağılmıştır. Örneğin okulların yaptığı modern kovanların eskilerinden daha kullanışlı ve daha ucuz olduğunu ya da öğretmenin köydeki ekonomik gelişmenin merkezi olduğunu gördükten sonra köylüler öğretmene 1sınmıştır (Başgöz, 2005: 176). Toplumsal bir yapıyla bütünleşmenin maddi bir zemini bulunduğunun ortaya konulmuş olması sosyolojik açıdan gerçekte materyalist bir gözlemdir. Alt sınıfların devrimci ya da yenilikçi toplumsal kurumları benimsemeleri, bu kurumların "geleneğe uygun olması" ya da "olmamasıyla" belirlenmemektedir. Tanışıklık hiç kuşkusuz önemli bir değişken olmakla birlikte, öncelikle bu kurumların kendi yaşamını sürdürmesine ve gönenç düzeyini yükseltebilmesiyle belirlenmektedir. Geniş kesimlerin toplumsal kurumlara bağlılıkları idealler ya da sözlerle değil, somut önlemler yoluyla olur.

Nüfusun belirgin bir çoğunluğunun köylülüğe dayandığı bir toplumda okul, aynı zamanda küçük bir ziraat işletmesi, bir çalışma merkezi olmalıdır. Bahçıvanlık, çobanlık, üreticilik ve tarım okulun içinde duvarlarla sınırlanmış sınıflarda öğrenilemez. Okulun arazisinde çalışmak zorunluluğu, gençleri köy ekonomisi için gerekli elemanlar olmaya yöneltecektir. Öğretmen köyün dışından gelen ve görevi bitince evine dönecek bir eğitimci olmamalı, kendi geçimi ve yaşamı köylülerin geçimi ve yaşamıyla birleşmiş bir eğitimci olmalıdır. Eğitim, iş temeli üzerine kurulmal1; öğretmenin köyde bir evi, bir işletmeye sahip olması gerekmektedir (Başgöz, 2005: 143). Bu kuramsal saptamalar ışığında Başgöz, Türk eğitim tarihinde "köy eğitmenleri" ve "köy enstitüleri" uygulamalarını içinde bulundukları dönem içinde Türkiye'nin toplumsal gerçeklerine en uygun eğitim düzenlemeleri olduğunu belirtmektedir. Gözleme dayalı bu saptamalar, Başgöz'ün eğitim sosyolojisi açısından üzerinde durulması gereken ikinci temel başlı̆̆ını oluşturmuştur.

\section{Sonuç}

Eğitim sosyolojisi açısından İlhan Başgöz'ün önemi, Türk modernleşmesi sürecinde eğitim kurumunu toplumsal ve ekonomik temelleriyle birlikte incelemiş olmasıdır. Örneğin Köy Eğitmenleri Projesi ya da Köy Enstitüleri incelenirken enstitülerin toplumsal amaçları, hangi toplumsal sınıfların çıkarlarına uygun oldukları, hangi toplumsal sınıfları huzursuz ettikleri inceleme alanına sokulduğunda, konu toplumsal ve ekonomik temelleriyle birlikte incelenmiş olmaktadır. Herhangi bir kurumsal yapının siyaset ve ekonomiyle ilişkisi içinde incelenmesi sosyoloji açısından özgün bir yöntemdir. Özellikle sınıfsal içerikli çözümlemeler, Türk modernleşmesinin tarihsel gelişimine ilişkin açılamalarda yeterince kullanılmamaktadır. Bu durum daha çok, sosyolojinin kendisiyle ilgilidir. 19. yüzyılda kentsoylu (burjuvazi) sınıfların toplumu açıklama ve düzeni koruma ihtiyaçlarının bir ürünü olarak tarih sahnesine çıkan sosyoloji, sınıfsal çelişkileri konu dışında bırakmaya eğilimli olmuştur. Bu yöntem anlayışı, günümüzde Türk modernleşmesini açıklamaya girişen sosyolojik çözümlemelerin pek çoğu için geçerlidir. Yine de şunun belirtilmesi gerekir ki, Başgöz'ün materyalist yöntemi 
benimsemiş bir toplumbilimci olduğunu belirtmek için elimizde yeterli veri kaynağı bulunmamaktadır. Şimdilik söylenebilecek tek şey, eğitim kurumunu açıklarken bunu çoğunlukla ve gerçeğe uygun biçimde somut yapılardan yola çıkarak gerçekleştirmiş olmasıdır.

Eğitim sosyolojisi merkezinden bakıldığında bu makalede Başgöz’ün kuramsal yaklaşımı iki başlık altında toplanmıştır. Birinci olarak Başgöz’e göre eğitim kurumu, diğer toplumsal koşulların bir ürünü olduğu gibi onlar tarafından belirlenir. Siyasetin ve ekonominin eğitim kurumu üzerindeki etkisini önemsemeyen bir eğitim uygulaması başarılı olamayacaktır. Bu açıdan bakıldığında toplumsal sorunların çözümünde eğitimin işlevi, diğer kurumları da içine alan devrimci ya da halkçı değişimlerle birlikte somut olarak görülebilir. İkinci başlık ise eğitimin toplumsal ihtiyaçları karşıladığı ölçüde toplumsal amaçlarına ulaşabileceğidir. Örneğin nüfusun ezici çoğunluğunun köye ve köylüye dayandığg bir toplumsal yapıda, eğitim köyün ekonomik ihtiyaçlarıyla bütünleştiği ölçüde kurumsal işlevlerini yerine getirebilir. İlhan Başgöz bu nedenle kentsoylu (burjuva) eğitim felsefesinin dışına çıkarak, 20. yüzyılın ilk yarısında Türkiye'de işe dayalı bir eğitimin gerekliliği üzerinde durmuş, Köy Enstitüleri uygulamasını önemsemiştir. Bununla birlikte şunun altını çizilmesi gerekmektedir. Türkiye'nin toplumsal yapısı değişmektedir. 20. yüzyılın ilk yarısındaki Türkiye'nin toplumsal yapısı ile bugünkü yapı arasında büyük ayrım noktaları bulunmaktadır. Bu nedenle Başgöz’ün kuramsal yaklaşımından yola çıkılarak Köy Enstitülerinin yeniden açılması gerektiği gibi bir sonuca ulaşmak yanlıştır. Çıkarılabilecek tek sonuç, yöntem alanındadır. Örneğin Türkiye toplumunun günümüzde emek yoluyla geçinen toplumsal sınıflarının ihtiyaçlarının saptanması ve bu ihtiyaçlar doğrultusunda somut eğitim uygulamaları denenmesi önerilebilir.

\section{Kaynaklar}

Althusser, L. (2014). İdeoloji ve devletin ideolojik aygıtları, (A. Tümertekin, Çev.). İstanbul: İthaki. Başaran, İ. (1974). Tonguç yolu. İstanbul: Varlık.

Başgöz, İ. (2005). Türkiye’nin eğitim çıkmazı ve Atatürk. İstanbul: Pan.

Başgöz, İ. (2019). Atatürk'e ve Türkiye Cumhuriyeti'ne selam, sevgi ve saygı. Ankara: Ürün.

Eskicumal1, A. (2003). Eğitim ve toplumsal değişme: Türkiye'nin değişim sürecinde eğitimin rolü, 1923-1946, Boğaziçi Üniversitesi Ĕ̌itim Dergisi, S.19 (2).

Mardin, Ş. (2017). Türkiye'de toplum ve siyaset. (M. Türköne ve T. Önder, Der.) İstanbul: İletişim. 